\title{
PRICE CLUSTERING AFTER THE INTRODUCTION OF BITCOIN FUTURES
}

\author{
AHMED S. BAIG ${ }^{*}$, OMAIR HAROON², NASIM SABAH ${ }^{3}$ \\ 1. Texas Tech University, United States and Lahore University of Management Sciences, Pakistan \\ 2. Lahore University of Management Sciences, Pakistan \\ 3. Framingham State University, United States
}

* Corresponding Author: Rawls College of Business, Texas Tech University, Lubbock, TX, 79409, United States and Suleman Dawood School of Business, Lahore University of Management Sciences,

Lahore, Punjab, 54792, Pakistan $\bowtie$ ahmed.baig@ttu.edu

\begin{abstract}
Economic theory suggests that introduction of derivative contracts can improve the informational efficiency of the underlying asset prices (Danthine, 1978). In this study, we examine the impact of the introduction of Bitcoin futures on price clustering in Bitcoin. Our findings suggest that price clustering in Bitcoin meaningfully decreases after the introduction of its futures contracts.
\end{abstract}

Keywords: Bitcoin, Cryptocurrency, Futures, Market Efficiency, Price Clustering

JEL classification: G10, G11, G12, G14

\section{Introduction}

Economic theory asserts that derivative contracts, such as futures, tend to act as an information enhancement mechanism and provide stability to the underlying assets (Danthine, 1978). A broad stream of empirical literature lends support to this theory. For instance, Skinner (1989) and Conrad (1989) find a decrease in the variance of underlying equity prices following the introduction of derivative contracts. Similarly, Damodaran and Lim (1991) study the options listings on CBOE and AMEX and find that listing of options leads to decrease in variance and an improvement in informational efficiency of underlying stock prices.

In this study, we extend this line of literature and examine the impact of the introduction of Bitcoin futures on the clustering of Bitcoin prices. Price clustering, a term coined by Harris (1991), refers to the instances whereby certain (round) pricing increments tend to be more commonly observed than the others. Since changes in prices should follow a random walk, clustered prices question the process of price discovery and in turn the notion of market efficiency (Fama, 1970). This phenomenon of price clustering has been observed in various markets including commodities, currencies, equities and fixed income. Urquhart (2017) documents clustering in daily Bitcoin prices on round increments and attributes it to the negotiation hypothesis (Harris, 1991). Baig, Blau and Sabah (2019) find evidence of price clustering in Bitcoin at the intra-day level. Building on the works of Harris (1991), Baig and Sabah (2019) show that price clustering is due to uncertainty and stocks that are more heavily traded by informed investors such as short sellers have lower instances of price clustering. Since the introduction of Bitcoin futures on December 10 th 2017 exogenously increased the possibility of institutional ownership 
and short selling ', we hypothesize that price clustering in Bitcoin should decrease following this event. In a related study, Köchling, Müller and Posch (2019) use various autocorrelation tests to show that the efficiency of Bitcoin prices improved following the launch of its futures contracts. Another study by Blau, Griffith and Whitby (2020) suggests that introducing futures contracts improved the informational environment of the entire cryptocurrency market.

Using intraday data from top five cryptocurrency exchanges, we investigate clustering in Bitcoin prices before and after introduction of Bitcoin futures at the CBOE. To the extent that the introduction of Bitcoin futures improved the price discovery process in Bitcoin markets, we should expect a decrease in price clustering in Bitcoin Post the introduction of its futures contracts. The results from various time-series tests suggest that price clustering in Bitcoin indeed decreases after the introduction of its futures. These results remain robust to corrections for heteroscedasticity and serial correlation. Our results are also robust to different time windows surrounding the introduction of Bitcoin futures. Our findings indicate that the introduction of Bitcoin futures makes the Bitcoin market more informationally efficient. Therefore, governments should carefully design Bitcoin-related regulation to ease the Bitcoin futures trading in order to protect the consumers and investors.

\section{Data and Methodology}

We gather transaction level bitcoin data from https://bitcoincharts.com. This website provides data in several currencies from different active and inactive exchanges. We collect Bitcoin/USD data for 88 exchanges and keep the top five exchanges based on daily average trading volume. These five exchanges are: Bitfinex, Bitsta, Mtgox, Coinbase, and Btce. Each transaction record contains date, time, price and volume. We collect Bitcoin market capitalization, average transaction fee and turnover from https://bitinfocharts.com. We delete observations with price less than five dollars. Bitcoin futures were first introduced on 10 December 2017. We collect data from one year before to one year after the introduction of Bitcoin futures. Thus, our final sample spans from 11 December 2016 to 10 December 2018.

From transaction level data, we create one daily measure of price clustering, $C L_{-}$Ratio, for the Bitcoin prices. The variable captures the percentage of daily transaction occurs at round increment of $\$ 0.05$. We calculate our control variables as follows: Market Cap is the closing Price multiplied by number of Bitcoin outstanding, Transaction_Fee is the average transaction fee for all the Bitcoin transactions during the day. Turnover is the trading volume scaled by no. of Bitcoins. Range Volatility is Log (Maximum Price) - Log (Minimum Price) using daily prices.

\section{Results}

Table 1 provides the statistics that summarize the sample. The mean Bitcoin price clustering at round increments of $\$ 0.05$ is about $35 \%$ in our sample. In a world where changes in prices follow a random walk the mean price clustering would be about $20 \%$. So, we have an abnormal level of Bitcoin price clustering in our sample that is consistent

\footnotetext{
1 Figlewski and Webb (1993) show that derivatives improve the informational and transactional efficiency of the stock market by inhibiting the constraints to short selling activity.
} 
with previous studies. The mean values for volume, market capitalization, transaction fee, price, range volatility and turnover are 0.03 million, 95.79 billion, 3.82, $\$ 5659.60,0.08$ and 1.81 respectively.

\section{Table 1:Summary Statistics}

\begin{tabular}{l|cccccc}
\hline & \multicolumn{7}{|c}{ BTC } \\
\hline & $(\mathbf{1})$ & $\mathbf{( 2 )}$ & $\mathbf{( 3 )}$ & $\mathbf{( 4 )}$ & $\mathbf{( 5 )}$ & (6) \\
\hline Variable & Obs & Mean & Median & Std.Dev & Minimum & Maximum \\
\hline CL_ratio & 502 & 0.35 & 0.36 & 0.05 & 0.23 & 0.48 \\
Volume (million) & 502 & 0.03 & 0.02 & 0.02 & 0.01 & 0.16 \\
Market_Cap (billion) & 502 & 95.79 & 108.31 & 64.09 & 12.41 & 315.52 \\
Transaction Fee & 502 & 3.82 & 1.24 & 7.37 & 0.26 & 55.16 \\
Price & 502 & 5659.60 & 6247.88 & 3794.31 & 774.08 & 19039.01 \\
Range Volatility & 502 & 0.08 & 0.07 & 0.06 & 0.01 & 0.43 \\
Turnover (*1000) & 502 & 1.81 & 1.50 & 1.22 & 0.34 & 10.82 \\
\hline
\end{tabular}

The data for BTC has been sourced from 5 exchanges (Bitfinex, Bitstamp, Mtgox, Coinbase, Btce). CL ratio is clustering ratio calculated as a proportion of trades in a day carried out at $\$ 0.05$ increments scaled by total trades in that day. Volume is the trading volume in a day. Market Cap is the total market capitalization on close of market in a day. Transaction fee is the average fees for the Bitcoin transactions. Price is closing price. Range Volatility is Log (Maximum Price) - Log (Minimum Price) for the day. Turnover is the daily trading volume scaled by total number of Bitcoin outstanding. The data period is 11 Dec 2016 to 10 Dec 2018

In our first set of tests we run a time series regression as follows:

$$
\begin{aligned}
& C L \_ \text {Ratio_t }=\beta \_0+\beta \_1 \text { Post_t }+\beta \_2 L N \_ \text {MarketCap_t }+\beta \_3 \text { Price_t }+\beta \_4 \text { RangeVolatility Post } \\
& t+\beta \_5
\end{aligned}
$$

Turnover_t $+\beta \_6$ Transaction Fee_t $t+\epsilon_{-} t$

Post is an indicator variable that takes a value of one Post the launch of Bitcoin futures on the CBOE on December 10 th 2017 . Table 2 presents the results from the time-series regressions following equation 1. Column 1 presents the results for 3 -months before and after sample period, column 2 presents the results for 6-months before and after sample period, column 3 presents the results for 9 -months before and after sample period while column 4 presents the results for 12-months before and after sample period. We use Newy-West standard errors with up to 20 lags in all our regression specifications. Our results are also robust to Eicker-Huber-White standard errors. According to our hypothesis we should observe a decrease in price clustering in Bitcoin Post the implementation of its futures contracts. Therefore, we should observe a negative and significant Post coefficient. In columns 1 and 2 we observe economically strong but statistically insignificant negative coefficients on Post. In column 3 we observe a both economically and statistically significant negative coefficient on Post. In economic terms we see about a $3.7 \%$ decrease in price clustering in the 9 months following the launch of its futures. This price clustering phenomenon further significantly decreases by about $4.1 \%$ in the 12 months' horizon as shown in column 4.

In sum, our results from Table 2 suggest that price clustering indeed decreases for Bitcoin Post the launch of its futures contracts. This decrease becomes stronger across time and is strongest at the 12-month horizon. This is consistent with market participants requiring time to understand and fully utilize the opportunity to realize the benefits of the Bitcoin futures market. 
Table 2: Bitcoin Time Series Regressions

Standard errors in parentheses ${ }^{* * *} p<0.01, * * p<0.05,{ }^{*} p<0.1$

\begin{tabular}{|c|c|c|c|c|}
\hline & (1) & (2) & (3) & (4) \\
\hline & $\begin{array}{c}3 \text { Months Before } \\
\text { After }\end{array}$ & $\begin{array}{c}6 \text { Months Before } \\
\text { After }\end{array}$ & $\begin{array}{c}9 \text { Months Before } \\
\text { After }\end{array}$ & $\begin{array}{c}12 \text { Months Before } \\
\text { After }\end{array}$ \\
\hline & CL_Ratio & CL Ratio & CL Ratio & CL_Ratio \\
\hline Post & $\begin{array}{l}-0.014 \\
(0.009)\end{array}$ & $\begin{array}{l}-0.010 \\
(0.017)\end{array}$ & $\begin{array}{c}-0.037^{* * *} \\
(0.013)\end{array}$ & $\begin{array}{c}-0.041^{* * *} \\
(0.011)\end{array}$ \\
\hline LN_Market_Cap & $\begin{array}{c}0.094^{* * *} \\
(0.025)\end{array}$ & $\begin{array}{l}-0.036 \\
(0.023)\end{array}$ & $\begin{array}{l}-0.000 \\
(0.027)\end{array}$ & $\begin{array}{c}-0.032^{* *} \\
(0.015)\end{array}$ \\
\hline Price & $\begin{array}{l}-0.000 \\
(0.000)\end{array}$ & $\begin{array}{c}0.000^{* * *} \\
(0.000)\end{array}$ & $\begin{array}{c}0.000 \\
(0.000)\end{array}$ & $\begin{array}{c}0.000^{* * *} \\
(0.000)\end{array}$ \\
\hline Range Volatility & $\begin{array}{c}0.036 \\
(0.066)\end{array}$ & $\begin{array}{c}0.086 \\
(0.092)\end{array}$ & $\begin{array}{c}0.009 \\
(0.088)\end{array}$ & $\begin{array}{l}-0.042 \\
(0.087)\end{array}$ \\
\hline Turnover & $\begin{array}{c}12.580^{* * *} \\
(3.123)\end{array}$ & $\begin{array}{c}14.143^{* * *} \\
(4.906)\end{array}$ & $\begin{array}{c}23.043^{* * *} \\
(5.193)\end{array}$ & $\begin{array}{c}22.584^{* * *} \\
(4.925)\end{array}$ \\
\hline Transaction Fee & $\begin{array}{c}-0.001^{* * *} \\
(0.000)\end{array}$ & $\begin{array}{c}-0.001^{* * *} \\
(0.000)\end{array}$ & $\begin{array}{l}-0.000 \\
(0.001)\end{array}$ & $\begin{array}{l}-0.001 \\
(0.001)\end{array}$ \\
\hline Constant & $\begin{array}{c}-2.017^{* * *} \\
(0.610)\end{array}$ & $\begin{array}{l}1.177^{* *} \\
(0.568)\end{array}$ & $\begin{array}{c}0.300 \\
(0.650)\end{array}$ & $\begin{array}{l}1.070^{* * *} \\
(0.359)\end{array}$ \\
\hline NW SE & Yes & Yes & Yes & Yes \\
\hline R-squared & 0.6875 & 0.4171 & 0.4665 & 0.465 \\
\hline Observations & 126 & 251 & 379 & 502 \\
\hline
\end{tabular}

The data for BTC has been sourced from 5 exchanges (Bitfinex, Bitstamp, Mtgox, Coinbase, Btce). Post is a dummy variable that takes a value of 1 after December 10 th 2017 (introduction of Bitcoin futures) and zero otherwise. $C L$ ratio is clustering ratio calculated as a proportion of trades in a day carried out at $\$ 0.05$ increments scaled by total trades in that day. Volume is the trading volume in a day. LN_Market_Cap is the natural log of total market capitalization on close of market in a day Transaction fee is the average fees for the Bitcoin transactions. Price is closing price. Range Volatility is Log (Maximum Price) - Log (Minimum Price) for the day. Turnover is the daily trading volume scaled by total number of Bitcoin outstanding. The data period is 11 Dec 2016 to 10 Dec 2018. Standard errors are corrected using Newey-West error corrections with 20 lags.

In our final tests, we attempt to remove any general time-trends in our price clustering series in order to more robustly identify the impact of the introduction of Bitcoin futures on the price clustering phenomenon. To do so we follow Rapach, Ringgenberg and Zhou (2016) and de-trend our CL_Ratio series as follows:

$$
C L_{-}-\text {Ratio_t }=\beta \_0+\beta_{-} 1 \text { Time } t+\epsilon_{-} t \quad \text { for Time }=1, \ldots, T
$$

Time is a counter variable that counts time across our time-series. We estimate equation (2) using ordinary least squares (OLS) for our sample that spans from 11 December 2016 to 10 December 2018 and take the fitted residuals $\widehat{U}$, as our de-trended measure of price clustering in Bitcoin.

Next, we run the following OLS specification:

$$
\begin{gathered}
U_{-}^{\wedge} t=\beta_{-} 0+\beta_{-} 1 \text { Post }{ }_{-} t+\beta_{-} 2 L N_{-} \text {MarketCap }{ }_{-} t+\beta_{-} 3 \text { Price } t_{-}+\beta_{-} 4 \text { RangeVolatility } t+\beta \_5 \\
\text { Turnover } t+\beta \_6 \text { Transaction Fee } t+\epsilon_{-} t
\end{gathered}
$$


The sample period ranges from 12-months before and 12-months after the launch of Bitcoin futures. Dependent variable $\widehat{U}$ is the fitted residuals series obtained from equation (2). Our main independent variable is Post which is an indicator variable that takes a value of one Post the launch of Bitcoin futures on the CBOE on December $10^{\text {th }}$, 2017. The remaining control variables are defined the same way as in the earlier sections. Our regression specifications in columns (1) and (3) report Newy-West corrected standard errors, while regression specifications (2) and (4) report EickerHuber-White corrections. Our results are also robust to the use of a Tobit model.

Table 3: De-trended price clustering regressions surrounding the introduction of Bitcoin futures

\begin{tabular}{|c|c|c|c|c|}
\hline \multicolumn{5}{|c|}{ Panel A: Time Trend Regressions } \\
\hline & TIME & CONSTANT & OBSERVATIONS & R-SQUARED \\
\hline CL_RATIO & $\begin{array}{c}-0.000^{* * *} \\
(0.000)\end{array}$ & $\begin{array}{c}0.390^{* * *} \\
(0.004)\end{array}$ & 502 & 0.152 \\
\hline \multicolumn{5}{|c|}{ Panel B: De-trended Price Clustering Regressions } \\
\hline & $\begin{array}{c}\text { (1) } \\
C L \stackrel{\text { Ratio }}{ }\end{array}$ & $\begin{array}{c}(2) \\
C L \stackrel{\text { Ratio }}{ }\end{array}$ & $\begin{array}{c}(3) \\
\widehat{U}\end{array}$ & $\begin{array}{c}(4) \\
\widehat{U}\end{array}$ \\
\hline Post & $\begin{array}{c}-0.041^{* * *} \\
(0.011)\end{array}$ & $\begin{array}{c}-0.041^{* * *} \\
(0.005)\end{array}$ & $\begin{array}{l}-0.016^{*} \\
(0.009)\end{array}$ & $\begin{array}{c}-0.016^{* * *} \\
(0.005)\end{array}$ \\
\hline LN_Market_Cap & $\begin{array}{c}-0.032^{* *} \\
(0.015)\end{array}$ & $\begin{array}{c}-0.032^{* * *} \\
(0.006)\end{array}$ & $\begin{array}{c}-0.006 \\
(0.014)\end{array}$ & $\begin{array}{l}-0.006 \\
(0.005)\end{array}$ \\
\hline Price & $\begin{array}{c}0.000^{* * *} \\
(0.000)\end{array}$ & $\begin{array}{c}0.000^{* * *} \\
(0.000)\end{array}$ & $\begin{array}{c}0.000^{* * *} \\
(0.000)\end{array}$ & $\begin{array}{c}0.000^{* * *} \\
(0.000)\end{array}$ \\
\hline Range Volatility & $\begin{array}{c}-0.042 \\
(0.087)\end{array}$ & $\begin{array}{c}-0.042 \\
(0.079)\end{array}$ & $\begin{array}{l}-0.041 \\
(0.079)\end{array}$ & $\begin{array}{l}-0.041 \\
(0.073)\end{array}$ \\
\hline Turnover & $\begin{array}{c}22.584^{* * *} \\
(4.925)\end{array}$ & $\begin{array}{c}22.584^{* * *} \\
(4.625)\end{array}$ & $\begin{array}{c}21.593^{* * *} \\
(4.618)\end{array}$ & $\begin{array}{c}21.593^{* * *} \\
(4.419)\end{array}$ \\
\hline Transaction Fee & $\begin{array}{l}-0.001 \\
(0.001)\end{array}$ & $\begin{array}{c}-0.001^{* *} \\
(0.000)\end{array}$ & $\begin{array}{c}-0.001^{* *} \\
(0.000)\end{array}$ & $\begin{array}{c}-0.001^{* * *} \\
(0.000)\end{array}$ \\
\hline Constant & $\begin{array}{c}1.070^{* * *} \\
(0.359)\end{array}$ & $\begin{array}{c}1.070 * * * \\
(0.132)\end{array}$ & $\begin{array}{c}0.092 \\
(0.343)\end{array}$ & $\begin{array}{c}0.092 \\
(0.126)\end{array}$ \\
\hline SE Type & Newy-West & White & Newy-West & White \\
\hline Observations & 502 & 502 & 502 & 502 \\
\hline R-squared & 0.465 & 0.465 & 0.424 & 0.424 \\
\hline
\end{tabular}

CL_Ratio is clustering ratio calculated as a proportion of trades in a day carried out at $\$ 0.05$ increments scaled by total trades in that day. Time is a counter variable. $\widehat{U}$ are the residuals from the regression of $C L \_$Ratio on the time counter variable. Volume is the trading volume in a day. $L N_{-}$Market_Cap is the natural log of total market capitalization on close of market in a day. Transaction fee is the average fees for the Bitcoin transactions. Price is closing price. Range Volatility is Log (Maximum Price) - Log (Minimum Price) for the day. Turnover is the daily trading volume scaled by total number of Bitcoin outstanding. The data period is 11 Dec 2016 to 10 Dec 2018. Standard errors are corrected using Newey-West error corrections with 20 lags in columns (1) and (3) and using White's corrections in columns (2) and (4).

Panels A and B of Table 3 report the results from the estimation of equations (2) and (3) respectively. In panel A we find a significant negative coefficient on the Time variable which suggests that price clustering has a general negative trend across our sample. According to our hypothesis Bitcoin price clustering should decrease Post implementation of its futures contracts and this decrease is independent of any general time-trend and is solely driven by the exogenous increase in synthetic short selling due to its futures. In panel B columns (3) and (4) we report the estimates from equation (3). 
In column (3) we incorporate the Newy-West corrections and find that our main independent variable of interest Post a negative and significant coefficient of 0.016 , this coefficient is significant at ten percent level. It suggests that price clustering in Bitcoin significantly decreases in the twelve months following the introduction of Bitcoin futures contracts. In column (4) we incorporate White's standard errors and find that Post has an economically similar negative coefficient but is statistically significant at one percent level. We note that our results in columns (3) and (4) are weaker in comparison to columns (1) and (2) where we have our original CL-Ratio as a measure of price clustering. This is consistent with the findings of equation (2) that, during our sample period, price clustering generally had a decreasing trend in Bitcoin markets. This result is consistent with the findings of Baig, Sabah and Winters (2019) who find a similar decreasing time-trend in price clustering in equities. These results also suggest several paths for future research. For instance, researchers could study and quantify the reasons of this negative time-trend in price clustering. Baig, Sabah and Winters (2019) suggest that this negative time-trend may be explained by an increase in algorithmic and high frequency trading (HFT) in equities. A similar comparison could be a valuable contribution to the cryptocurrency literature.

In sum, our findings suggest that Bitcoin price clustering indeed strongly decreases Post the launch of its futures. Moreover, this decrease in price clustering is not solely due to any general trend or economy-wide factor, instead, it is largely driven by the exogenous shock to Bitcoin prices due to the introduction of its futures contracts on the CBOE.

\section{Conclusion}

Urquhart (2017) documents clustering in bitcoin prices and attributes it to the negotiation hypothesis (Harris, 1991). Baig and Sabah (2019) find that short selling activity improves the informational efficiency of stock prices by reducing daily and intra-day price clustering. Derivatives are purported to reduce transaction frictions and improve price discovery process of the underlying security by reducing short selling constraints. To the extent that the introduction of Bitcoin futures improved the price discovery process in Bitcoin markets, we should expect a decrease in price clustering in Bitcoin post the introduction of its futures contracts. The results from various time-series tests suggest that price clustering in Bitcoin indeed decreases following the launch of its futures contracts.

\section{References}

Baig, A. S., \& Sabah, N. (2019). Does short selling affect the clustering of stock prices? The Quarterly Review of Economics and Finance, Forthcoming.

Baig, A., Blau, B. M., \& Sabah, N. (2019). Price clustering and sentiment in bitcoin. Finance Research Letters, 29, 111-116.

Baig, A., Sabah, N., \& Winters, D. (2019). Have Stock Prices become more Uniformly Distributed? Economics Bulletin, 39(2), 1242-1250.

Blau, B., Griffith, T., \& Whitby, R. (2020). Comovement in the Cryptocurrency Market. Economics Bulletin, 40(1), 448-455. 


\section{PRICE CLUSTERING AFTER THE INTRODUCTION OF BITCOIN FUTURES}

Conrad, J. (1989). The price effect of option introduction. The Journal of Finance, 44(2), 487-498.

Damodaran, A., \& Lim, J. (1991). The effects of option listing on the underlying stocks' return processes. Journal of Banking \& Finance, 15(3), 647-664.

Danthine, J. P. (1978). Information, futures prices, and stabilizing speculation. Journal of Economic Theory, 17(1), 79-98.

Fama, E. F. (1970). Efficient capital markets: A review of theory and empirical work. The journal of Finance, 25(2), 383-417.

Figlewski, S., \& Webb, G. P. (1993). Options, short sales, and market completeness. The Journal of Finance, 48(2), 761-777.

Harris, L. (1991). Stock price clustering and discreteness. The Review of Financial Studies, 4(3), 389-415.

Köchling, G., Müller, J., \& Posch, P. N. (2019). Does the introduction of futures improve the efficiency of Bitcoin? Finance Research Letters, 30, 367-370.

Rapach, D. E., Ringgenberg, M. C., \& Zhou, G. (2016). Short interest and aggregate stock returns. Journal of Financial Economics, 121(1), 46-65.

Skinner, D. J. (1989). Options markets and stock return volatility. Journal of Financial Economics, 23(1), 61-78.

Urquhart, A. (2017). Price clustering in Bitcoin. Economics letters, 159, 145-148. 